\title{
Static and Vibration Analysis of an Aluminium and Steel Bus Frame
}

\author{
Fatma Rebaïne*, Mohamed Bouazara, Ahmed Rahem, Lyne St-Georges \\ Department of Applied Sciences, University of Quebec at Chicoutimi, Chicoutimi, Quebec, Canada \\ Email: ^fatma.rebaine@uqac.ca
}

How to cite this paper: Rebaïne, F., Bouazara, M., Rahem, A. and St-Georges, L. (2018) Static and Vibration Analysis of an Aluminium and Steel Bus Frame. World Journal of Mechanics, 8, 112-135. https://doi.org/10.4236/wjm.2018.84010

Received: March 20, 2018

Accepted: April 27, 2018

Published: April 30, 2018

Copyright $\odot 2018$ by authors and Scientific Research Publishing Inc. This work is licensed under the Creative Commons Attribution International License (CC BY 4.0).

http://creativecommons.org/licenses/by/4.0/

\begin{abstract}
The transport sector is increasing day by day to satisfy the global market requirement. The bus is still the main mode of intercity transportation in Canada. Despite, an essentially unchanged conception, the total weight of the bus has increased by over $25 \%$ during the last three decades. To solve this problem, industrialists have moved to the use of light metals in the transportation field. Therefore, use of lightweight materials, such as aluminum is essential to reduce the total weight of bus. In this study, the focus is on the bus frame as it represents $30 \%$ of the total weight and it is the most stressed part of the bus. Its life duration is more important compared to that of all other elements. Thus, a study of the static and vibratory behavior would be very decisive. In this article, two types of analysis are carried out. First is the modal analysis to determine the natural frequencies and the mode shapes using a developed dynamic model of the bus. Because if any of the excitation frequencies coincides with the natural frequencies of the bus frame, then resonance phenomenon occurs. This may lead to excessive deflection, high stress concentration, fatigue of the structure and vehicle discomfort. In this case, the results analysis shows that the natural frequencies are not affected by the change of material. The second type of analysis is the linear static stress analysis to consider the stress distribution and deformation frame pattern under static loads numerically. For the numerical method, the frame is designed using SolidWorks and the analysis is made using Ansys WorkBench. The maximum Von Mises stress obtained for the static loading is in the same order for the three chassis frames studied. But in the case of the aluminium frame, the weight of $764 \mathrm{~kg}$ was reduced.
\end{abstract}

\section{Keywords}

Bus, Frame, Aluminum, Steel, Modal Analysis, Static, Stress Analysis 


\section{Introduction}

A bus frame represents the most stressed section in terms of excitation from the road or in terms of its main function of supporting structure. There have been several recent studies carried out at the level of this supporting structure, whether for car, truck, or bus. The focus of this different study was on design, geometry, static analysis, modal, and dynamic analysis. As for the work on design, different digital tools were used as Abaqus, Ansys, Catia, and SolidWorks. The most recent analyses were applied using the Ansys Workbench interface. The use of such finite element tools helps in accelerating design by minimizing the number of physical tests, thereby reducing the cost and the time.

Several static and modal studies have been established to evaluate the performance of the chassis. Among these works, M. Chandrasekar et al. [1] carried out an improved design of a ladder truck chassis using FE analysis under static and modal conditions. The results, obtained by using Ansys, show that shifting the third cross member away from the second gives better results. Mukesh Patil et al. [2] made a static and modal analysis by using Ansys Workbench for a tanker truck chassis to be able to evaluate maximum stress and natural frequencies of the frame. The results show that the maximum stress exceeds the ultimate tensile strength indicating that the structure is not safe. In this case, more investigations should be applied regarding design and load caring. Udhay Kiran S. et al. [3] present a linear static analysis of leader truck chassis by using Catia and Nastran Patran Workbench. Stress analysis is carried out on the chassis to find the critical point of maximum stress. In order to improve performance, geometry has to be modified. Manpreet Singh Bajwa et al. [4] performed a static load analysis and stress optimization of a tata super ace chassis using standard techniques of vehicle modification. Two methods of optimisation were used, mainly boxing and reinforcement techniques. The reinforcement technique using Ansys simulator at the highly stressed regions is found to be the most effective technique. There is also study of the vibration characteristics of the truck chassis and the stress distribution under various loading conditions presented by Teo Han Fui et al. [5]. The mode shape results determine the suitable mounting location of engine and suspension system. Another work regarding truck chassis is presented by Roslan Abd Rahman et al. [6] for the stress analysis of a heavy truck chassis loaded by static forces using Abaqus. The results show that the critical point of stress is significant as the value of safety factor is below the recommended value. In this case, more investigations should be performed to improve this result. Another work of structural static analysis of the truck chassis using Ansys workbench is presented by Vijaykumar V. Patel et al. [7]. A comparison between analytical and numerical results was presented. The numerical simulation obtained by Ansys for the Von Mises and shear stress was bigger 10\% than result of the analytical calculation. This static analysis was performed to obtain the maximum stress and shear deformation of the chassis using static loading to be able to evaluate the capacity of the total frame. 
Regarding the modal analysis [1] [2] [5] [8], these studies were joined with the static analysis. It consists of calculating and representing the natural frequencies and mode shapes of the chassis. For the work presented by Kallappa Khannukar [8], the modal analysis was carried out using both analytical and FEA techniques. The chassis is optimized by varying the design parameters with the help of the acceleration response of the system. Regarding other studies, the static analysis was used to evaluate the possibility of chassis weight reduction [9] [10] [11]. M. Ravi Chandra et al. [9] have presented the modeling of an existing heavy vehicle chassis with three different composite materials subjected to the same pressure as that of steel. They are made to be able to evaluate the reduction of the weight which is now the main issue in automobile industries. The results show that there is a reduction in weight of $73 \%$ to $80 \%$ compare to the steel frame, but the natural frequency is different. The work of Akshay Jain et al. [10] shows the possibility of reducing stress developed in the chassis frame and increase load carrying capacity. The study focused on the static load analysis with different thickness of chassis frame. The results show a weight reduction of about $1.2 \%$ and an increase in capacity by $40 \%$. For the study presented by Patel Vitaykumar V. et al. [12], a sensitive analysis was also carried out regarding the weight reduction by varying frame web height and thickness using $\mathrm{FE}$ analysis in Ansys Workbench. The results show a weight reduction by $6.68 \%$ of the chassis frame.

The variation of chassis member thickness was also used [12] [13] [14] to reduce weight, stress or to carry loads beyond the payload [15]. The chassis section was also varied in the work of Abhishek Singh et al. [16] to evaluate which section is more strength full than the other sections. The different sections are C, I, rectangular box (hollow) and rectangular box (intermediate). From simulations, it is observed that the rectangular box (intermediate) represents the more strength full section. The material was also varied [17] [18] to evaluate the variation in stress and deformation of the chassis frame.

\section{Bus Frame Model}

This study focuses on the static and vibration analysis of aluminium and steel chassis of the bus. The frame or chassis is the most significant part used for supporting the bus structure as it is subjected to several of both dynamic and static forces. In this section, the chassis specification, the frame loading and the different frame motion are presented.

\subsection{Frame Specification}

The bus frame model specified for this study consists of a single axle in front and tandem axles at the back with total length of 10.02 meters. Figure 1 present the bus frame model components and dimensions. It is the most common chassis used in buses. It has two long side members (longitudinal beams) and 5 cross members (transversal beams) joined together by welding. 
The dimensions of the longitudinal and the transversal beams constituting the frame chassis are presented in Figure 2. It is a "C" channel section which is used for these beams; it has a good resistance to bending [15].

To be able to reduce the weight of the existing standard steel frame (steel 1018-HR, steel 710C), the 6061-T6 aluminum alloy material was selected for this study. The characteristics of this aluminum alloy made it useful in the automotive field. The properties of the three materials are shown in Table 1. The vibration analysis and static loading of the frames made with these three materials are presented in this work.

\subsection{Frame Loading}

Regarding the loading, Quebec ministry of transportation [20] guideline states that in the case of this specified frame, the standard of the loads limits is equal to $18,000 \mathrm{~kg}$. This value represents the sum of the allowable loads for each category
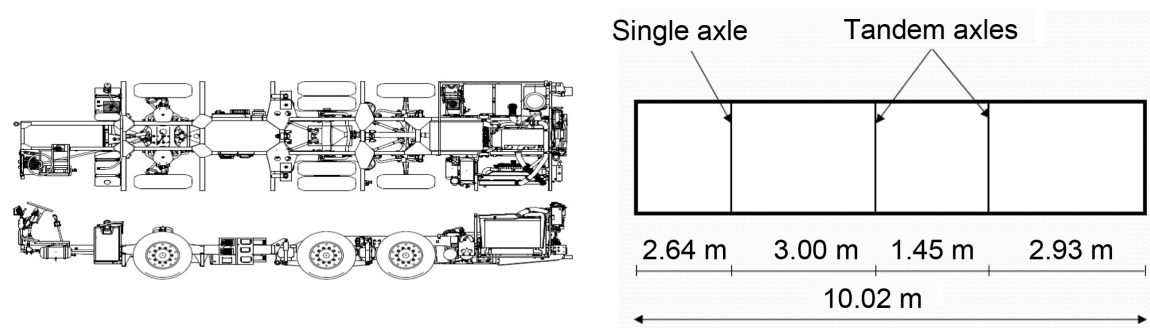

Figure 1. Bus frame model [19].

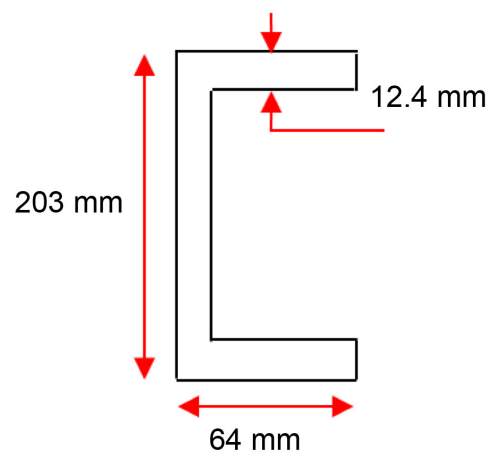

Longitudinal beam

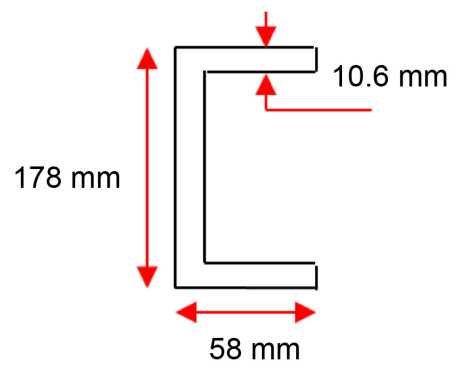

Transversal beam

Figure 2. Longitudinal and transversal beams.

Table 1. Properties of the three materials.

\begin{tabular}{cccc}
\hline Properties & Aluminium 6061-T6 & Steel 1018-HR & Steel 710C \\
\hline Young's modulus & $7.31 \times 10^{10} \mathrm{~N} / \mathrm{m}^{2}$ & $210 \times 10^{10} \mathrm{~N} / \mathrm{m}^{2}$ & $207 \times 10^{10} \mathrm{~N} / \mathrm{m}^{2}$ \\
Density & $2700 \mathrm{~kg} / \mathrm{m}^{3}$ & $7800 \mathrm{~kg} / \mathrm{m}^{3}$ & $7800 \mathrm{~kg} / \mathrm{m}^{3}$ \\
Poisson ratio & 0.33 & 0.28 & 0.30 \\
Tensile strength & $310 \mathrm{MPa}$ & $475 \mathrm{MPa}$ & $620 \mathrm{MPa}$ \\
Elastic limit & $275 \mathrm{MPa}$ & $275 \mathrm{MPa}$ & $550 \mathrm{Mpa}$ \\
\hline
\end{tabular}


of axles. The mass of the major considered elements for this study are presented in Table 2.

For the case of an aluminum frame, the total static loading $Q_{s}$ is equal to:

$$
\begin{gathered}
Q_{s}=18000-\left(Q_{3-1}+Q_{4}+Q_{5}+Q_{6}\right)=15087 \mathrm{~kg} \\
Q_{s}=148003.5 \mathrm{~N}
\end{gathered}
$$

For the tank and engine loads, they are applied separately then,

$$
Q_{s 1}=Q_{s}-\left(Q_{1}+Q_{2}\right)=13081 \mathrm{~kg}=128324.64 \mathrm{~N}
$$

This static loading is applied on the longitudinal beam. There are two longitudinal beams, then $Q_{\mathrm{s} 1}$ is divided by two and it is uniformly distributed on each beam.

Load acting on the single beam:

$$
\frac{128324.64}{2}=64162.32 \mathrm{~N} / \text { beam }
$$

- Beam pressure

$$
P_{\text {beam }}=\frac{Q_{\text {beam }}}{S_{\text {beam }}}=100253.62 \mathrm{~N} / \mathrm{m}^{2}
$$

- Tank pressure

$$
P_{\text {tank }}=\frac{Q_{\text {tank }}}{S_{\text {tank }}}=4248.92 \mathrm{~N} / \mathrm{m}^{2}
$$

- Engine pressure

$$
P_{\text {engine }}=\frac{Q_{\text {engine }}}{S_{\text {engine }}}=5299.89 \mathrm{~N} / \mathrm{m}^{2}
$$

For the steel frame, the load acting on the single frame is equal to $60,419.80$ $\mathrm{N} /$ beam and the beam pressure is equal to $94,217.50 \mathrm{~N} / \mathrm{m}^{2}$.

\subsection{Dynamic Frame Motion}

The frame is subjected to different motions as shown in Figure 3. The roll angle represents motion along the longitudinal axis. This motion is generated by the forces that are acting on the frame side. The pitch angle represents motion along

Table 2. Mass of the considered elements of this study.

\begin{tabular}{cc}
\hline Elements & Mass $(\mathrm{kg})$ \\
\hline Filled tank $\left(Q_{1}\right)$ & 476 \\
Engine $\left(Q_{2}\right)$ & 1530 \\
Aluminum frame $\left(Q_{3-1}\right)$ & 404 \\
Steel frame $\left(Q_{3-2}\right)$ & 1167 \\
Front axle $\left(Q_{4}\right)$ & 724 \\
Rear axle 1 $\left(Q_{5}\right)$ & 1224 \\
Rear axle 2 $\left(Q_{6}\right)$ & 561 \\
\hline
\end{tabular}




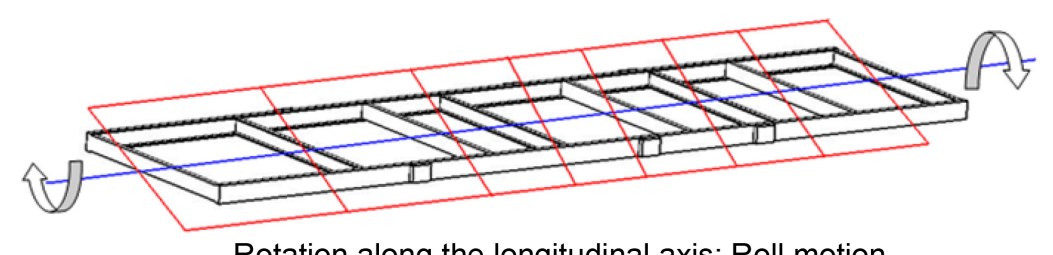

Rotation along the longitudinal axis: Roll motion

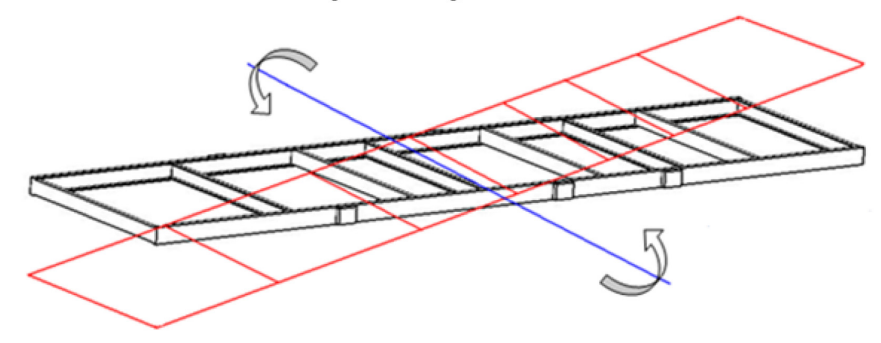

Rotation along the transversal axis: Pitch motion

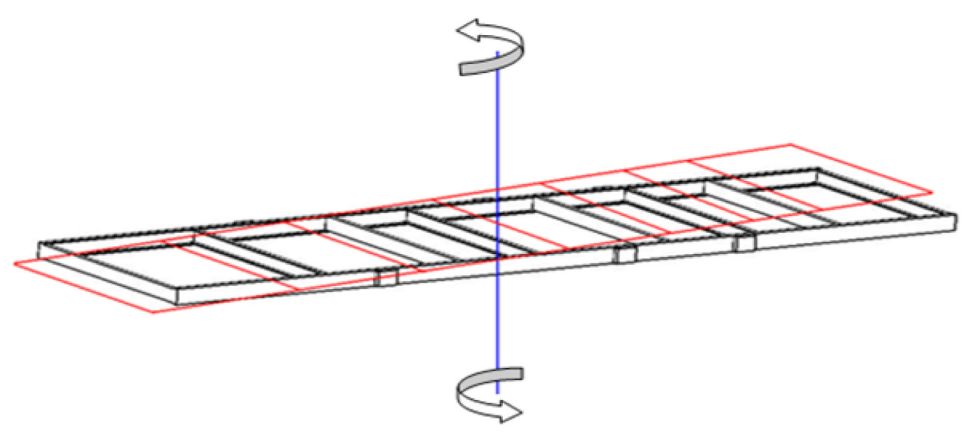

Rotation along the vertical axis: Yaw motion

Figure 3. Frame motion.

the transverse axis; it is a top downward motion. The yaw angle represents the motion along the vertical axis. This yaw angle is not predominant compared to the pitch and roll angles. Therefore, in this study the focus was set on pitch and roll angles only. The vertical motion was also studied.

\section{Three-Dimensional Dynamic Frame Model}

To be able to evaluate the motion of the bus frame, a three-dimensional dynamic model of the frame was developed. This model is presented in Figure 4; it is composed of six suspensions. This model has nine degrees of freedom; the first three degrees of freedom are related to the vertical motion, the pitch motion, and the roll motion in the bus. The other six-left degrees of freedom represent the vertical motion of the six suspensions.

The different parameters involved in this model are presented as follows:

$Y_{1,2,3,4,5,6}$ : Vertical motion of the six suspensions.

$Y_{7}$ : Vertical motion of the bus.

$\theta_{7}$ : Pitch bus rotating angle.

$\varnothing_{7}$ : Roll bus rotating angle.

$U_{i}$ : Input excitation at the wheel $i$.

The different parameters values of this model are shown in Table 3. 


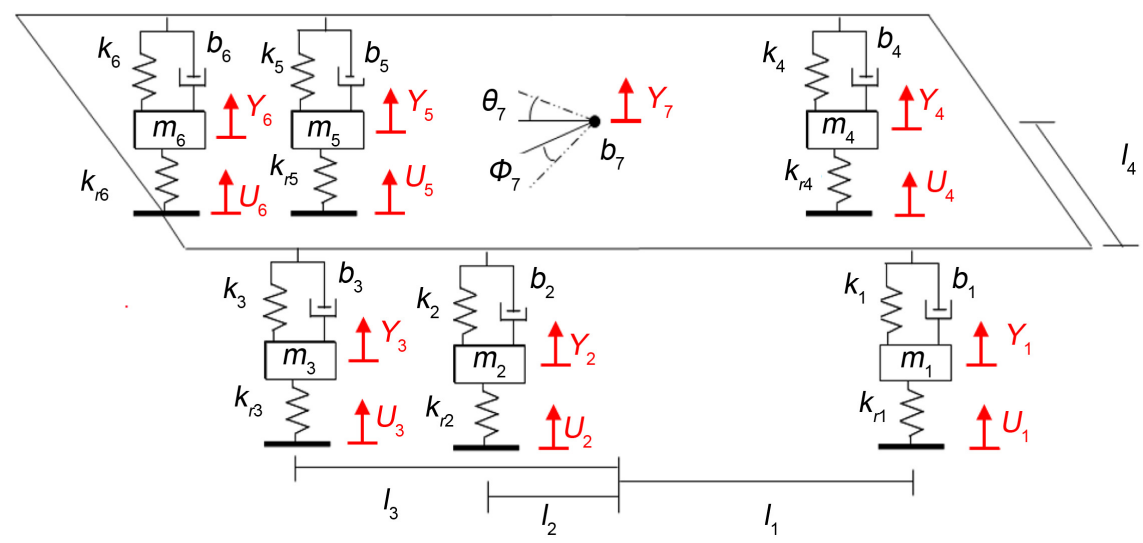

Figure 4. Three-dimensional model of the bus frame.

Table 3. Three-dimensional model parameters.

\begin{tabular}{ccc}
\hline Definition & Symbol $(\mathrm{Unit})$ & Value \\
\hline Bus mass & $m_{7}(\mathrm{~kg})$ & $15,491.5$ \\
Pitch moment & $I_{\theta}\left(\mathrm{kg} \cdot \mathrm{m}^{2}\right)$ & $149,951.42$ \\
Roll moment & $I_{\varnothing}\left(\mathrm{kg} \cdot \mathrm{m}^{2}\right)$ & $20,000.64$ \\
Distance (center gravity-wheel 1) & $l_{1}(\mathrm{~m})$ & 2.25 \\
Distance (center gravity-wheel 2) & $l_{2}(\mathrm{~m})$ & 0.81 \\
Distance (center gravity-wheel 3) & $l_{3}(\mathrm{~m})$ & 2.25 \\
Lateral distance & $l_{4}(\mathrm{~m})$ & 1.25 \\
Suspension rigidity for 1 and 4 & $k_{1,4}(\mathrm{~N} / \mathrm{m})$ & 374,000 \\
Suspension rigidity for 2, 3, 5 and 6 & $k_{2,3,5,6}(\mathrm{~N} / \mathrm{m})$ & 435,000 \\
Suspension damping $i$ & $b_{i}(\mathrm{~N} \cdot \mathrm{s} / \mathrm{m})$ & 12,850 \\
Tire rigidity $i$ & $k_{r i}(\mathrm{~N} / \mathrm{m})$ & $2,800,000$ \\
Suspension mass for 1 and 4 & $m_{1,4}(\mathrm{~kg})$ & 362 \\
Suspension mass for 2 and 5 & $m_{2,5}(\mathrm{~kg})$ & 611.83 \\
Suspension mass for 3 and 6 & $m_{3,6}(\mathrm{~kg})$ & 280.42 \\
\hline
\end{tabular}

\subsection{Equation of Motion}

The equations of motion of the bus frame are written separately for the six wheel assemblies and later for the total frame.

1) Wheel assembly 1: equation of motion

This case represents a single degree of freedom, because there is only vertical motion possible. Then, the equation of motion can be written using Newton's second law as follows, where $i$ is the number of axle.

$$
\sum F=m_{i} \ddot{y}_{i}
$$

For positive displacement of the masses 1 and 7 and for positive rotation by pitch angle $\theta_{7}$ and roll angle $\varnothing_{7}$, the forces acting on the front side of the frame at the wheel 1 are represented in Figure 5. $U_{1}$ and $y_{1}$ represent the input excitation to the wheel 1 and the vertical motion of the axle 1 respectively. 


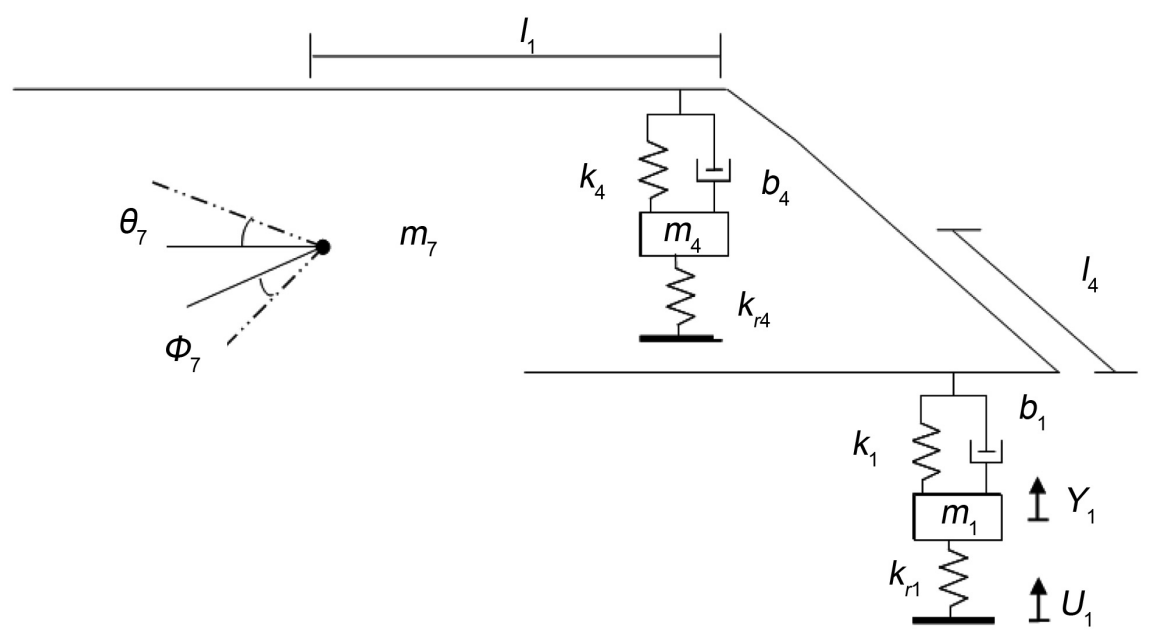

Figure 5. Three-dimensional wheel assembly 1.

- Tire equation

$$
F_{k r 1}=k_{r 1}\left(y_{1}-U_{1}\right)
$$

- Suspension equation

$$
\begin{gathered}
F_{k 1}=k_{1}\left[y_{1}-\left(y_{7}+l_{1} \theta_{7}+l_{4} \varnothing_{7}\right)\right] \\
F_{b 1}=b_{1}\left[\dot{y}_{1}-\left(\dot{y}_{7}+l_{1} \dot{\theta}_{7}+l_{4} \dot{\theta}_{7}\right)\right]
\end{gathered}
$$

All the forces opposing the motion are negative.

$$
m_{1} \ddot{y}_{1}=-k_{r 1}\left(y_{1}-U_{1}\right)-k_{1}\left[y_{1}-\left(y_{7}+l_{1} \theta_{7}+l_{4} \varnothing_{7}\right)\right]-b_{1}\left[\dot{y}_{1}-\left(\dot{y}_{7}+l_{1} \dot{\theta}_{7}+l_{4} \dot{\varnothing}_{7}\right)\right]
$$

The same procedure as the wheel assembly 1 was used to develop the different equations of motion for the wheel assemblies 2, 3, 4, 5 and 6.

2) Total frame: equation of motion

The frame of the bus, shown in Figure 4, is a rigid body with three degrees of freedom, namely, a bounce, a roll and a pitch. Consequently, the second law of Newton must be applied separately for each kind of motion:

$$
\sum F=m_{7} \ddot{y}_{7}, \sum M_{\theta}=I_{\theta 7} \ddot{\theta}_{7}, \sum M_{\varnothing}=I_{\varnothing 7} \ddot{\varnothing}_{7}
$$

- Bounce motion of the frame

For a positive vertical motion of the bus, all the suspensions elements act against it. Therefore, these forces are negative and the equation of bounce motion can be given by:

$$
\begin{aligned}
m_{7} \ddot{y}_{7}= & -k_{1}\left[\left(y_{7}+l_{1} \theta_{7}+l_{4} \varnothing_{7}\right)-y_{1}\right]-b_{1}\left[\left(\dot{y}_{7}+l_{1} \dot{\theta}_{7}+l_{4} \dot{\varnothing}_{7}\right)-\dot{y}_{1}\right] \\
& -k_{2}\left[\left(y_{7}-l_{2} \theta_{7}+l_{4} \varnothing_{7}\right)-y_{2}\right]-b_{2}\left[\left(\dot{y}_{7}-l_{2} \dot{\theta}_{7}+l_{4} \dot{\varnothing}_{7}\right)-\dot{y}_{2}\right] \\
& -k_{3}\left[\left(y_{7}-l_{3} \theta_{7}+l_{4} \varnothing_{7}\right)-y_{3}\right]-b_{3}\left[\left(\dot{y}_{7}-l_{3} \dot{\theta}_{7}+l_{4} \dot{\varnothing}_{7}\right)-\dot{y}_{3}\right] \\
& -k_{4}\left[\left(y_{7}+l_{1} \theta_{7}-l_{4} \varnothing_{7}\right)-y_{4}\right]-b_{4}\left[\left(\dot{y}_{7}+l_{1} \dot{\theta}_{7}-l_{4} \dot{\varnothing}_{7}\right)-\dot{y}_{4}\right]
\end{aligned}
$$




$$
\begin{aligned}
& -k_{5}\left[\left(y_{7}-l_{2} \theta_{7}-l_{4} \varnothing_{7}\right)-y_{5}\right]-b_{5}\left[\left(\dot{y}_{7}-l_{2} \dot{\theta}_{7}-l_{4} \dot{\varnothing}_{7}\right)-\dot{y}_{5}\right] \\
& -k_{6}\left[\left(y_{7}-l_{3} \theta_{7}-l_{4} \varnothing_{7}\right)-y_{6}\right]-b_{6}\left[\left(\dot{y}_{7}-l_{3} \dot{\theta}_{7}-l_{4} \dot{\varnothing}_{7}\right)-\dot{y}_{6}\right]
\end{aligned}
$$

\section{- Pitch motion of the frame}

For a positive pitch motion of the bus, all the suspension elements act against it. Therefore, these forces are negative and the equation of pitch motion can be given by:

$$
\begin{aligned}
I_{\theta 7} \ddot{\theta}_{7}= & -l_{1} k_{1}\left[\left(y_{7}+l_{1} \theta_{7}+l_{4} \varnothing_{7}\right)-y_{1}\right]-l_{1} b_{1}\left[\left(\dot{y}_{7}+l_{1} \dot{\theta}_{7}+l_{4} \dot{\varnothing}_{7}\right)-\dot{y}_{1}\right] \\
& -l_{2} k_{2}\left[\left(y_{7}-l_{2} \theta_{7}+l_{4} \varnothing_{7}\right)-y_{2}\right]-l_{2} b_{2}\left[\left(\dot{y}_{7}-l_{2} \dot{\theta}_{7}+l_{4} \dot{\varnothing}_{7}\right)-\dot{y}_{2}\right] \\
& -l_{3} k_{3}\left[\left(y_{7}-l_{3} \theta_{7}+l_{4} \varnothing_{7}\right)-y_{3}\right]-l_{3} b_{3}\left[\left(\dot{y}_{7}-l_{3} \dot{\theta}_{7}+l_{4} \dot{\varnothing}_{7}\right)-\dot{y}_{3}\right] \\
& -l_{1} k_{4}\left[\left(y_{7}+l_{1} \theta_{7}-l_{4} \varnothing_{7}\right)-y_{4}\right]-l_{1} b_{4}\left[\left(\dot{y}_{7}+l_{1} \dot{\theta}_{7}-l_{4} \dot{\varnothing}_{7}\right)-\dot{y}_{4}\right] \\
& -l_{2} k_{5}\left[\left(y_{7}-l_{2} \theta_{7}-l_{4} \varnothing_{7}\right)-y_{5}\right]-l_{2} b_{5}\left[\left(\dot{y}_{7}-l_{2} \dot{\theta}_{7}-l_{4} \dot{\varnothing}_{7}\right)-\dot{y}_{5}\right] \\
& -l_{3} k_{6}\left[\left(y_{7}-l_{3} \theta_{7}-l_{4} \varnothing_{7}\right)-y_{6}\right]-l_{3} b_{6}\left[\left(\dot{y}_{7}-l_{3} \dot{\theta}_{7}-l_{4} \dot{\varnothing}_{7}\right)-\dot{y}_{6}\right]
\end{aligned}
$$

- Roll motion of the frame

For a positive roll motion of the bus, all the suspension elements act against it. Therefore, these forces are negative and the equation of roll motion can be given by:

$$
\begin{aligned}
I_{\varnothing 7} \ddot{\varnothing}_{7}= & -l_{6} k_{1}\left[\left(y_{7}+l_{1} \theta_{7}+l_{4} \varnothing_{7}\right)-y_{1}\right]-l_{6} b_{1}\left[\left(\dot{y}_{7}+l_{1} \dot{\theta}_{7}+l_{4} \dot{\varnothing}_{7}\right)-\dot{y}_{1}\right] \\
& -l_{6} k_{2}\left[\left(y_{7}-l_{2} \theta_{7}+l_{4} \varnothing_{7}\right)-y_{2}\right]-l_{6} b_{2}\left[\left(\dot{y}_{7}-l_{2} \dot{\theta}_{7}+l_{4} \dot{\varnothing}_{7}\right)-\dot{y}_{2}\right] \\
& -l_{6} k_{3}\left[\left(y_{7}-l_{3} \theta_{7}+l_{4} \varnothing_{7}\right)-y_{3}\right]-l_{6} b_{3}\left[\left(\dot{y}_{7}-l_{3} \dot{\theta}_{7}+l_{4} \dot{\varnothing}_{7}\right)-\dot{y}_{3}\right] \\
& -l_{6} k_{4}\left[\left(y_{7}+l_{1} \theta_{7}-l_{4} \varnothing_{7}\right)-y_{4}\right]-l_{6} b_{4}\left[\left(\dot{y}_{7}+l_{1} \dot{\theta}_{7}-l_{4} \dot{\varnothing}_{7}\right)-\dot{y}_{4}\right] \\
& -l_{6} k_{5}\left[\left(y_{7}-l_{2} \theta_{7}-l_{4} \varnothing_{7}\right)-y_{5}\right]-l_{6} b_{5}\left[\left(\dot{y}_{7}-l_{2} \dot{\theta}_{7}-l_{4} \dot{\varnothing}_{7}\right)-\dot{y}_{5}\right] \\
& -l_{6} k_{6}\left[\left(y_{7}-l_{3} \theta_{7}-l_{4} \varnothing_{7}\right)-y_{6}\right]-l_{6} b_{6}\left[\left(\dot{y}_{7}-l_{3} \dot{\theta}_{7}-l_{4} \dot{\varnothing}_{7}\right)-\dot{y}_{6}\right]
\end{aligned}
$$

By making the change of variables as presented below:

$$
\begin{aligned}
& x_{1}=y_{1}, x_{2}=\dot{y}_{1}, x_{3}=y_{2}, x_{4}=\dot{y}_{2}, x_{5}=y_{3}, x_{6}=\dot{y}_{3}, \\
& x_{7}=y_{4}, x_{8}=\dot{y}_{4}, x_{9}=y_{5}, x_{10}=\dot{y}_{5}, x_{11}=y_{6}, x_{12}=\dot{y}_{6}, \\
& x_{13}=y_{7}, x_{14}=\dot{y}_{7}, x_{15}=\theta_{7}, x_{16}=\dot{\theta}_{7}, x_{17}=\varnothing_{7}, x_{18}=\dot{\varnothing}_{7}
\end{aligned}
$$

The state system of the three-dimensional frame dynamic model has been developed. It is composed of eighteen unidentified variables. This system was solved using the Matlab software and the transfer functions were calculated. The parameters $x_{1}, x_{3}, x_{5}, x_{7}, x_{9}$ and $x_{11}$ represent the vertical motion of the six 
suspensions of the frame. The vertical, the pitch and roll motions of the frame corresponding to the transfer functions are related to the parameters $x_{13}, x_{15}$ and $x_{17}$. The corresponding matrix is presented below.

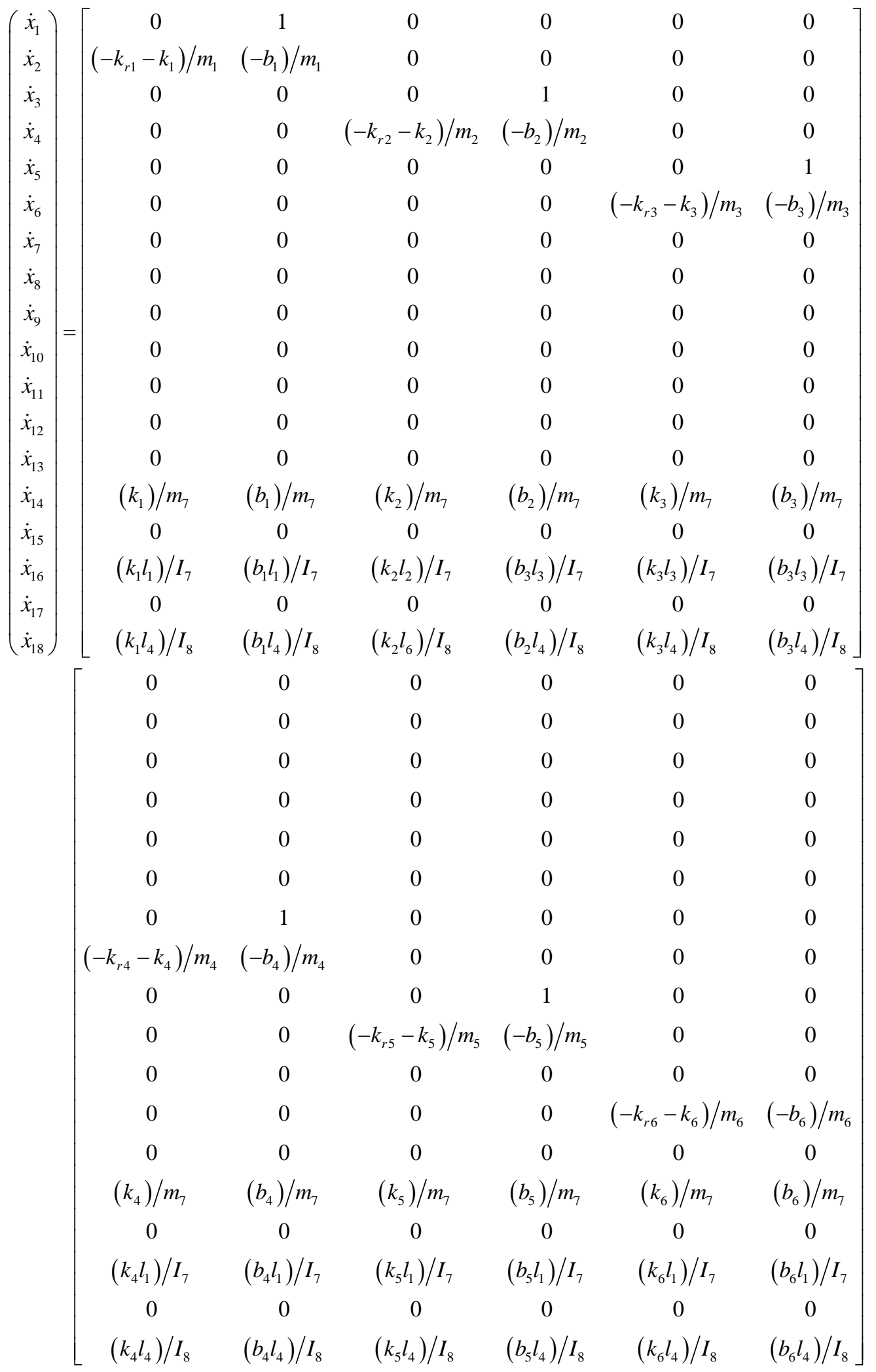




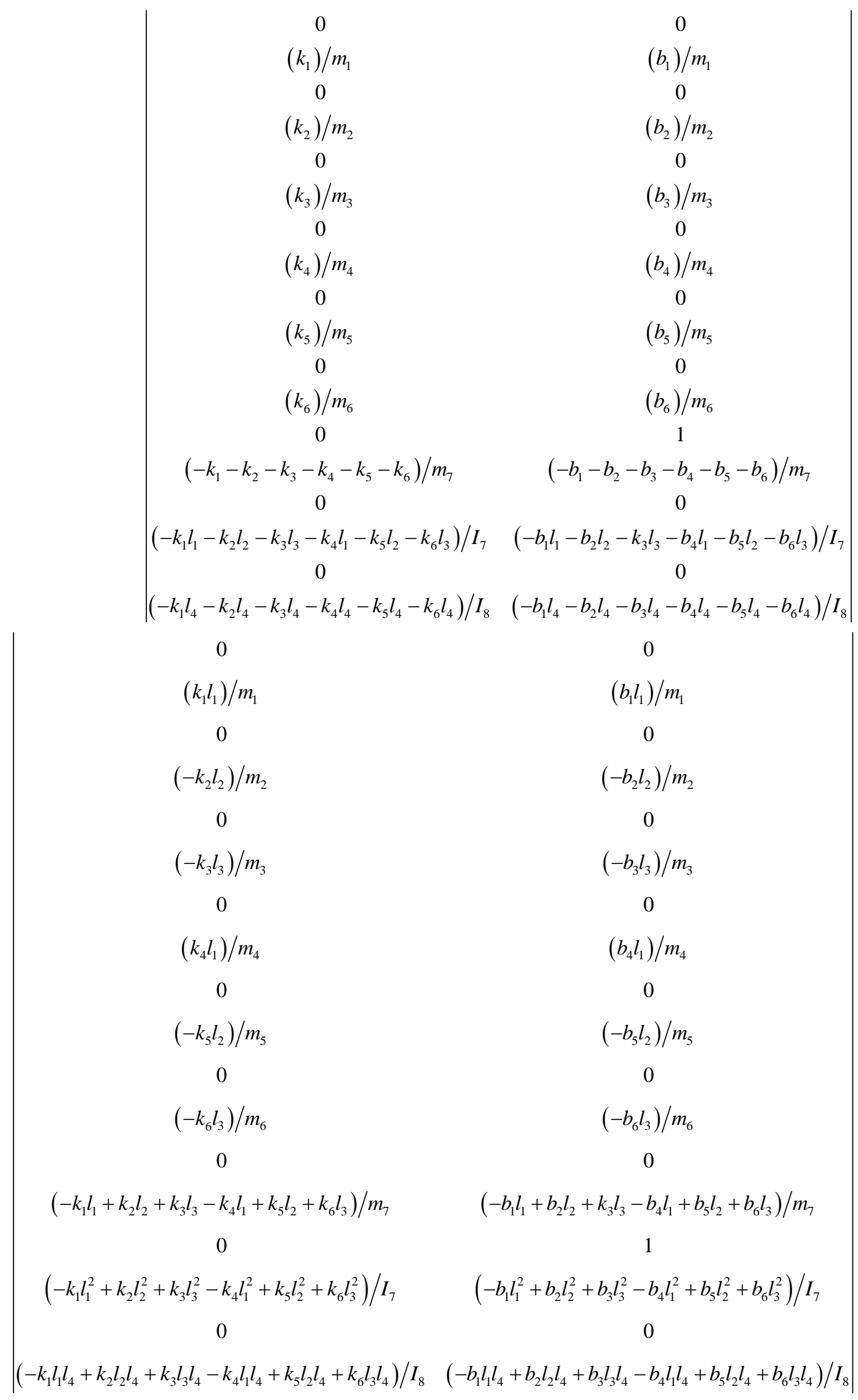




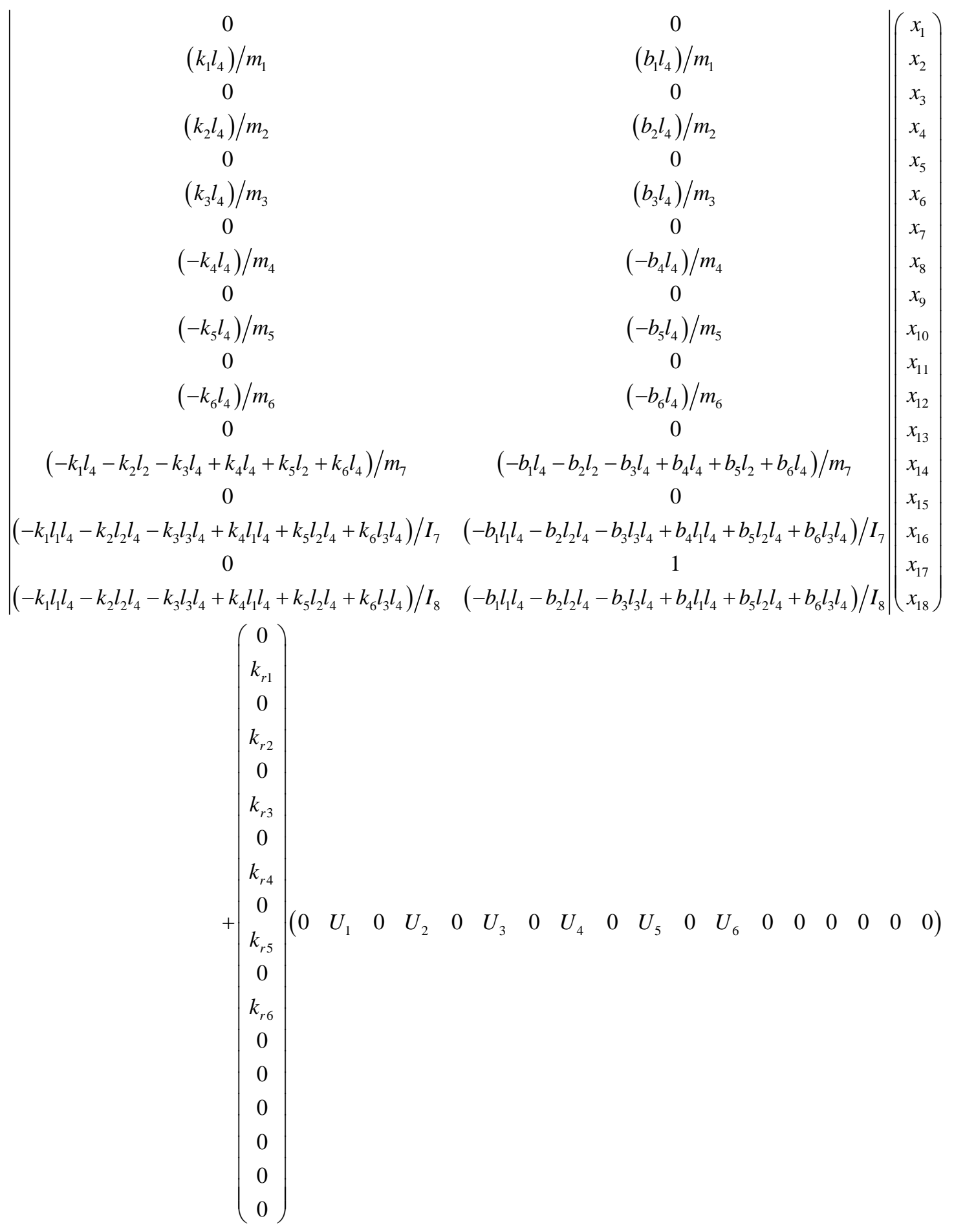

(17)

\subsection{Vibration Results}

Generally, the range of frequencies in the field of road vehicles varies between 1 and $20 \mathrm{~Hz}$. In the case of this study, by using the developed 3D model of the bus frame, the resonant frequencies were obtained. These frequencies are obtained with the bode diagram for the case of materials shown in Table 1 . The results 
obtained for these three cases are presented below.

- Aluminum 6061-T6 bus frame

The results of the resonance frequencies obtained in the case of the aluminum frame are presented in this section. Figure 6 shows bode diagram for the wheel assembly 1 of the frame. Bode diagram has two graphs, the first one is the amplitude as a function of the frequency; the second is the phase as a function of the frequency. Resonance occurs when the amplitude reaches to maximum and the phase is equal to $\pi / 2\left(90^{\circ}\right)$. Thus, in this case, the resonant frequency of the wheel assembly 1 is equal to $14.35 \mathrm{~Hz}$.

Figures 7-9 show the bode diagrams obtained for the total frame respectively in the case of bounce, pitch, and roll motion. For all three cases, the resonance frequency is equal to $1.80 \mathrm{~Hz}$. These frequency results are less than $20 \mathrm{~Hz}$, which corresponds to what is found in the literature [21].

- Steel 1018-HR and 710C bus frame

The comparison of the frequencies' resonance results obtained for the designed frame with different materials presented in Table 4 shows a very great similarity. Therefore, the material does not affect the resonant frequencies in this study case. This assumes that the use of aluminum instead of steel in the frame design does not affect the resonant frequencies of the bus frame.

\section{Structural Analysis}

A structural analysis of the frame chassis is presented in this section. This analysis includes a static study as well as a vibratory study. The materials used for this study are aluminum 6061-T6, steel 1018-HR and steel 710C. This analysis is

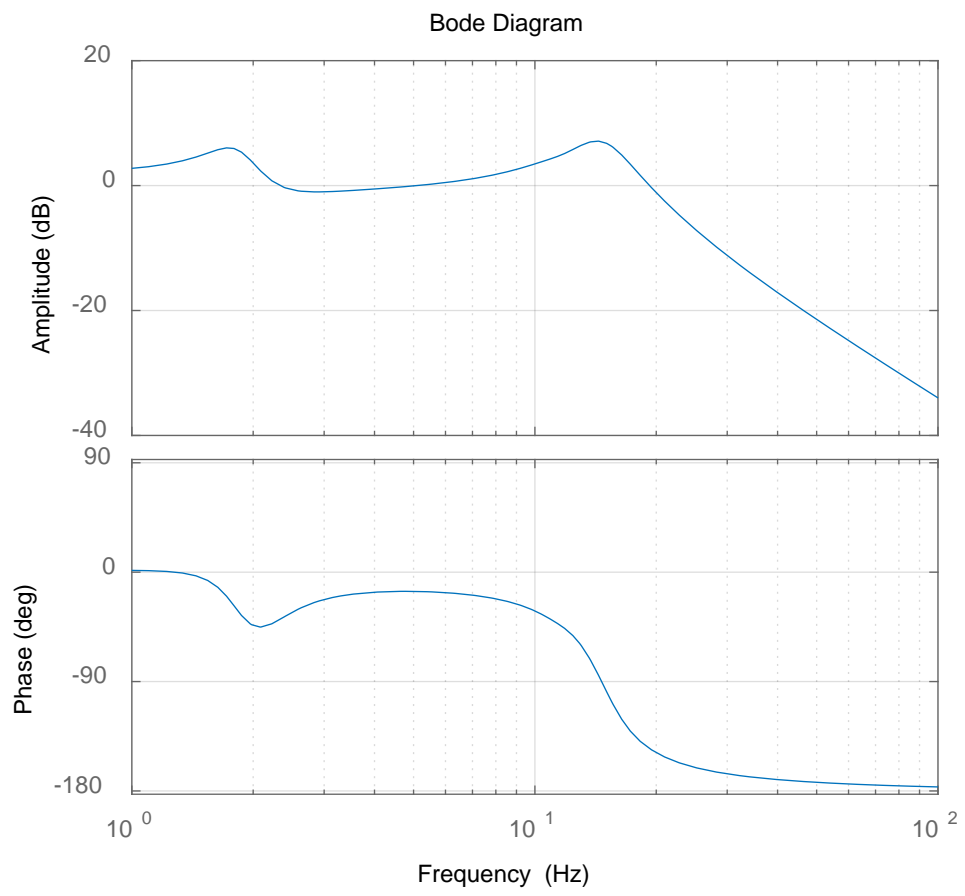

Figure 6. Bode Diagram-Wheel assembly 1. 


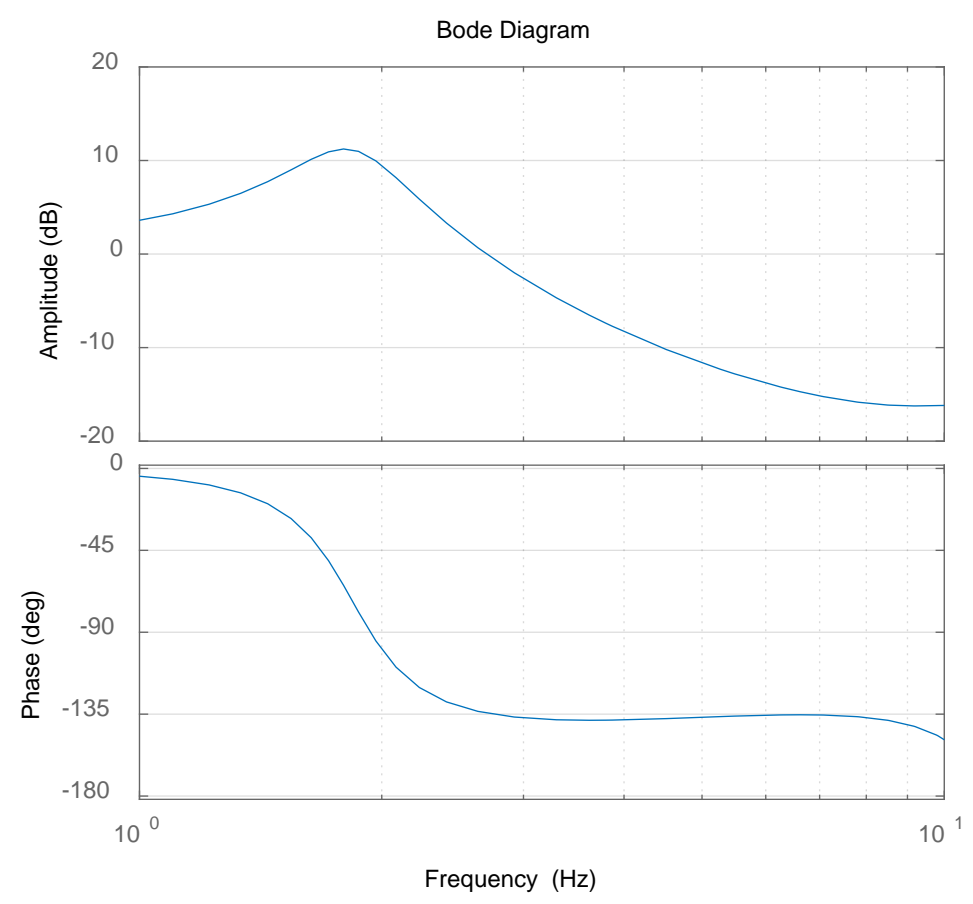

Figure 7. Bode Diagram-Bounce frame motion.

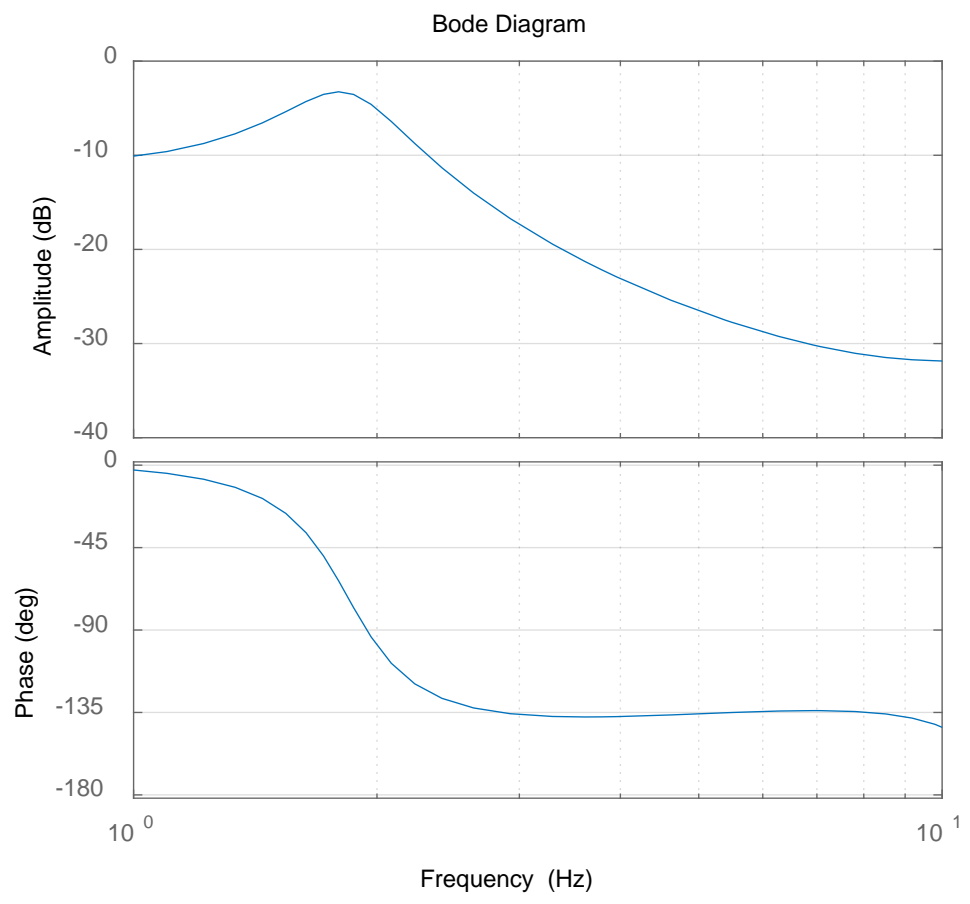

Figure 8. Bode Diagram-Pitch frame motion.

necessary to know the capacities of the aluminum chassis in comparison with those made of steel. The use of aluminum in the transport sector would make it possible to have a great advantage in terms of weight reduction, energy consumption and even durability [17] [18]. The design of the chassis was first realized on SolidWorks, subsequently the structural analyzes were done with the 


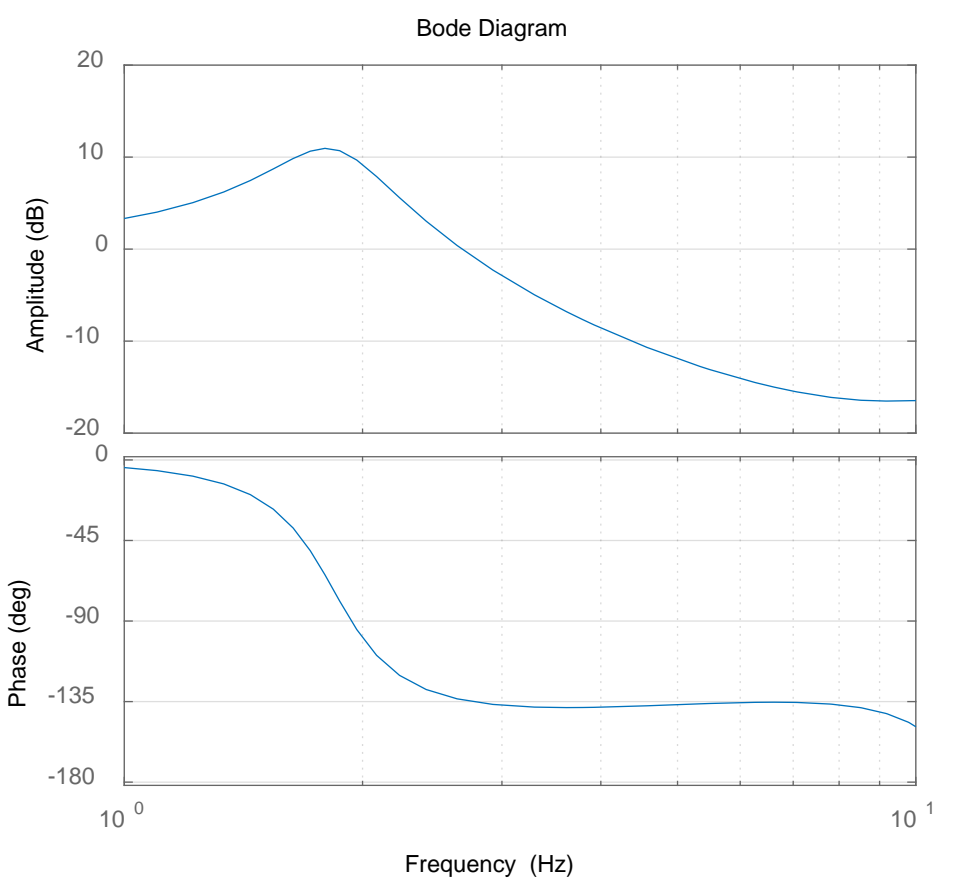

Figure 9. Bode Diagram-Roll frame motion.

Table 4. Frequency results of the bus frame for the three materials.

\begin{tabular}{cccc}
\hline Frequency & Aluminum 6061-T6 & $1018-\mathrm{HR}$ & $710 \mathrm{C}$ \\
\hline Wheel assembly 1 (Hz) & 14.35 & 14.40 & 14.40 \\
Bounce $(\mathrm{Hz})$ & 1.80 & 1.75 & 1.75 \\
Pitch $(\mathrm{Hz})$ & 1.80 & 1.75 & 1.75 \\
Roll $(\mathrm{Hz})$ & 1.80 & 1.75 & 1.75
\end{tabular}

tool of ANSYS Workbench. Many recent structural studies have been done using this software [1] [2] [4] [7] [9], which is why in this case the ANSYS tool was used.

\section{- Frame mushing}

In simulations, the first step consists in the choice of the material, subsequently the generation of the mesh followed by the boundary conditions and the loading part. It is the same mesh that is used for the three materials to be able to compare the results at the end.

The total frame is mushed with a tetrahedral element (Tet 10). In total, there is 1025281 elements and the number of nodes is equal to $1,738,446$. Figure 10 present the frame meshing.

\section{- Loading and boundary conditions}

The loading and boundary conditions of the aluminum and steel frames are presented in Figure 11. The loading conditions are assumed to be the same for steel and aluminum to be able to compare the results. In the case of aluminum frame, it is possible to add more weight $(764 \mathrm{~kg})$ to reach the maximum allowable loading limits. The static loads are assumed as a uniform distributed on the 


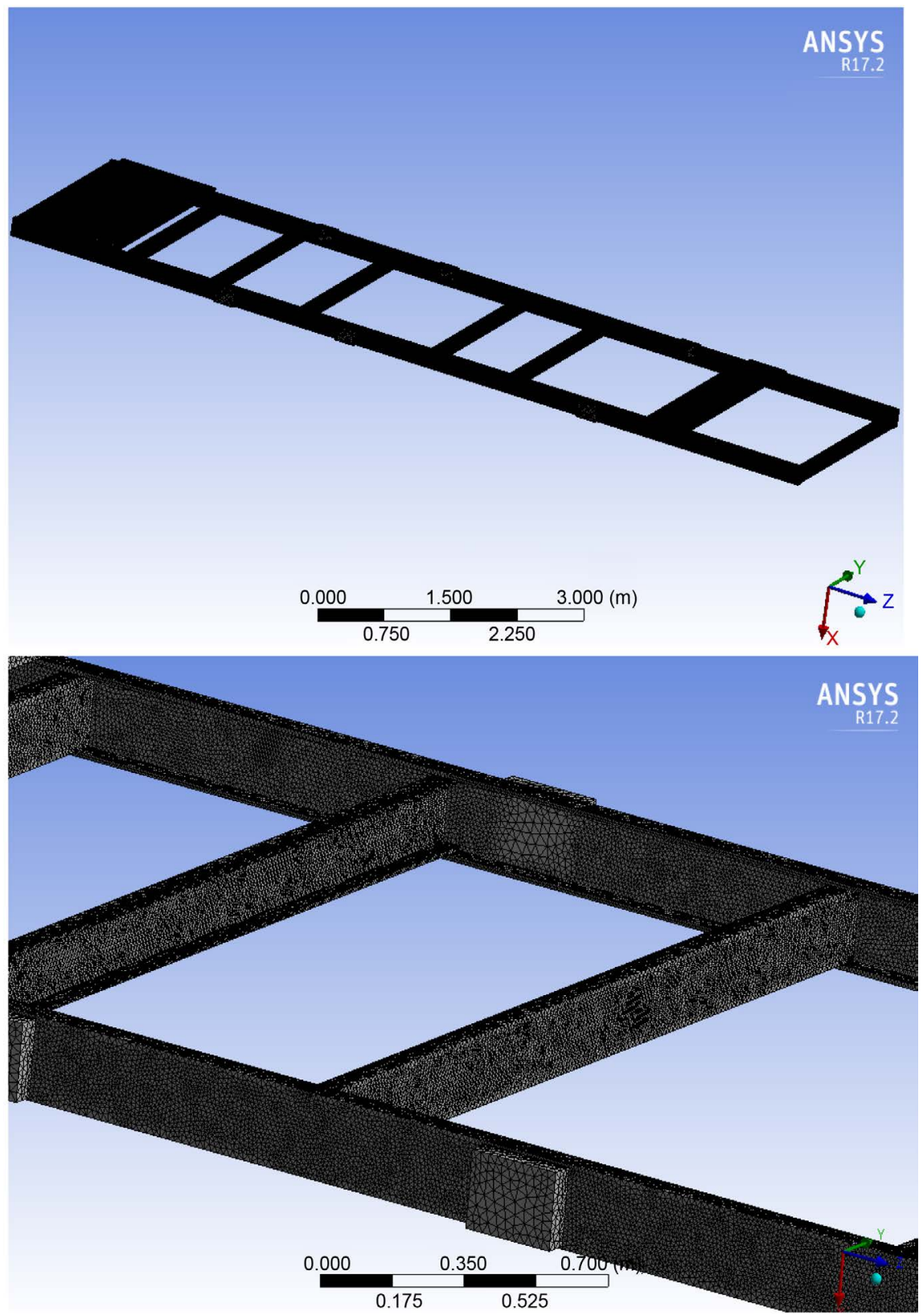

Figure 10. Tetrahedral mesh of the frame.

two longitudinal beams obtained from the maximum admissible loading of the Quebec Ministry of transportation for this frame category. There are six boundary conditions in this model. All these boundary conditions are applied on the well axles of the frame. Two are on the front and the four others in the rear.

\subsection{Static Analysis}

This study was carried out to compare the mechanical strengths due to the static loading of the aluminum frame with those designed in steel. For this, an analysis of the maximum stresses undergone by the chassis; evaluations of the total displacement as well as the stresses due to the shearing were realized. 


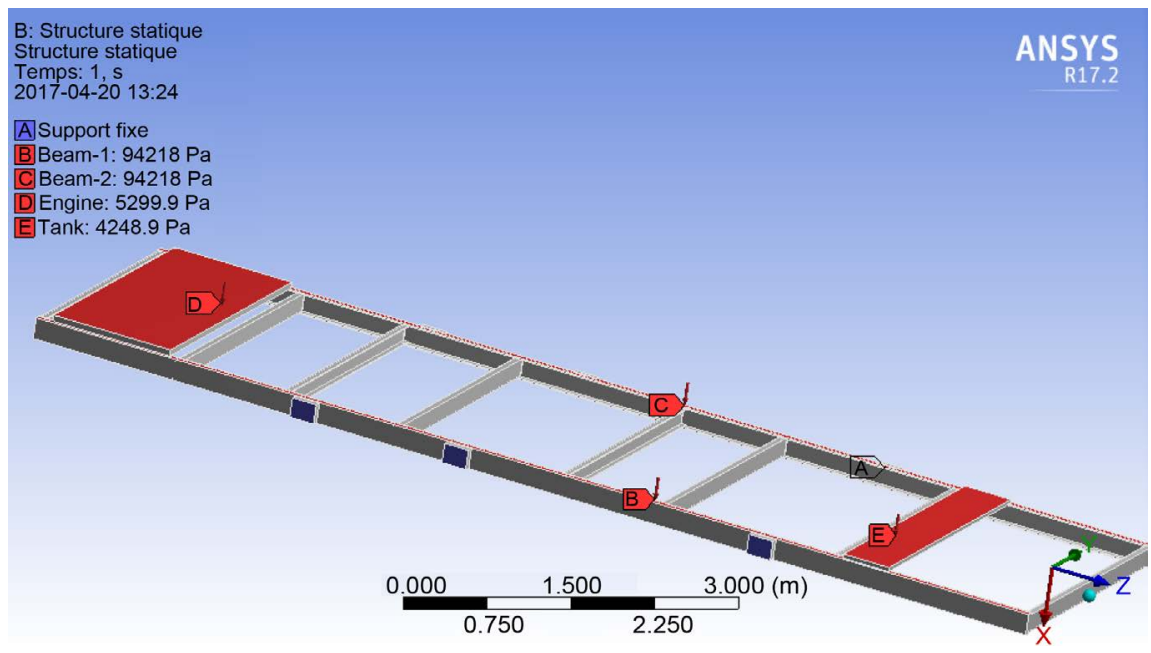

Figure 11. Loading conditions of the aluminum and steel frames.

- Aluminum 6061-T6

The static analysis of 6061-T6 aluminum frame is presented in this section. The values of the loads applied on the aluminum frame are presented in the section 2.2. For this static analysis, the maximum Van Mises stress equals to 195.30 MPa as shown in Figure 12(a) and Figure 12(b) is obtained near to the front axle. This value is overestimated du to the boundary conditions applied on the six axles locations. Another point is that the static loading applied during the simulation represents the maximum admissible loads allowed by Quebec ministry of transportation. The total displacement of aluminum frame presented in Figure 12(c) is equal to $0.038 \mathrm{~m}$ and the maximum shear stress presented in Figure 12(d) is equal to $102.50 \mathrm{MPa}$. The location of the maximum shear stress is the same as for the maximum Van Mises equivalent stress.

- Steel 1018-HR and 710C frames

Table 5 presents the comparison between static analysis results of aluminum and steel frames. The comparison shows that there is a small difference between aluminum and steel frame results. Then, the aluminum frame can be used as same as the steel frame.

The static analysis results obtained for the 1018-HR steel frame are presented in Figure 13. The same results were obtained for the 710C steel frame. If the safety factor $F_{s}$ is considered for the 6060-T6 aluminum and 1018-HR steel, the results will be:

$$
F_{s}=\frac{\text { Elastic limit } \sigma_{e}}{\text { Maximum stress } \sigma_{\text {max }}}
$$

For aluminum and steel frames, the safety factor is eqal respectively to 1.41 and 1.39. This means that there no a big difference between the capacity of these two material in case of the static loading.

\subsection{Modal Analysis}

In this section, the static analysis of the frames made by the three different 
materials was presented to evaluate the capacity of the aluminum frames compared to those made of steel that is used now in transportation. Another important case to evaluate, is the modal analysis. For this modal analysis, all degrees of

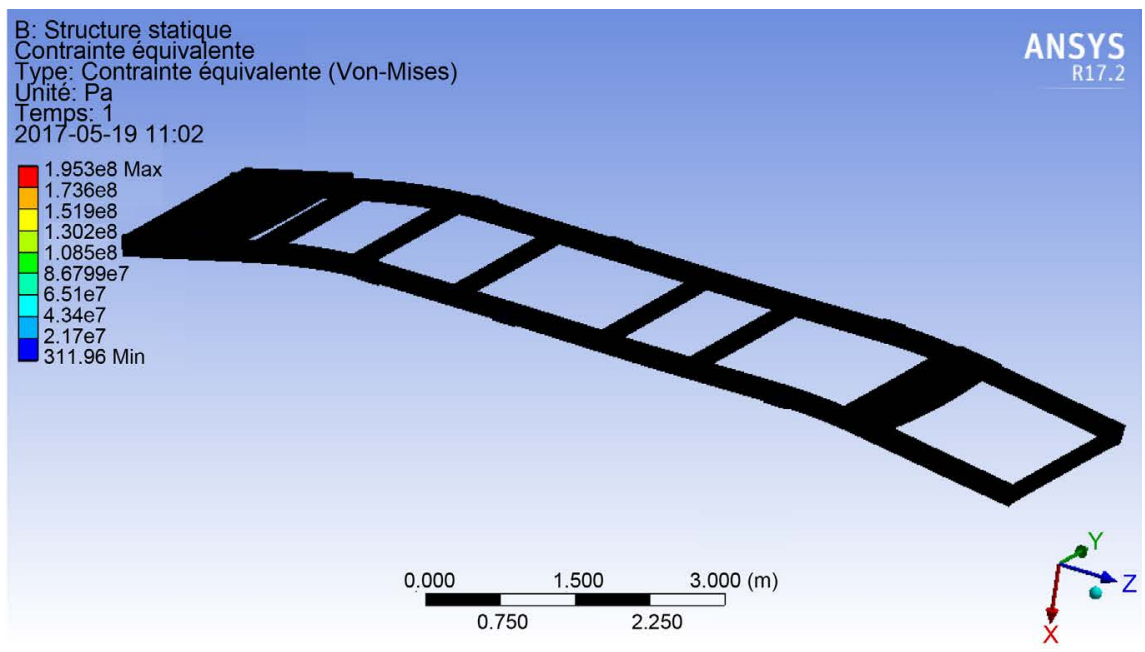

(a)

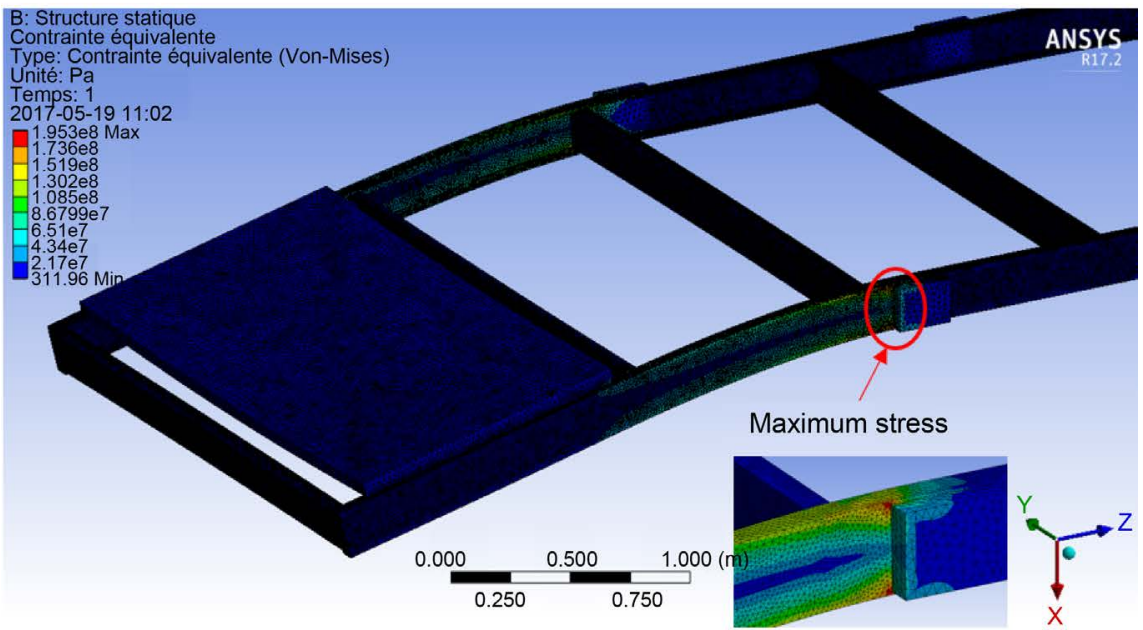

(b)

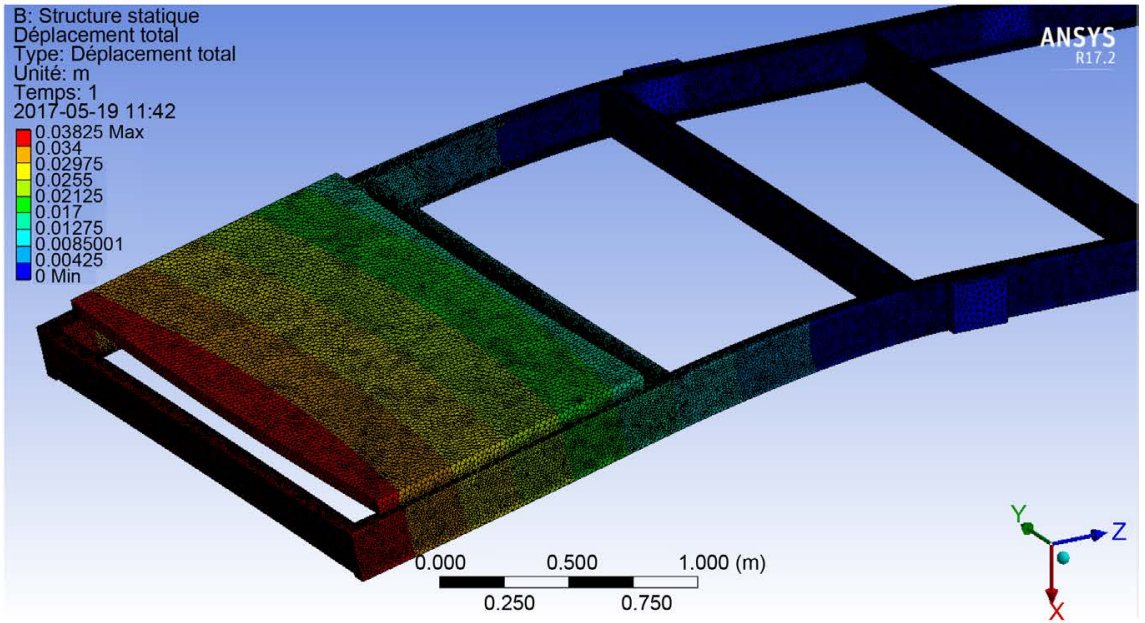

(c) 


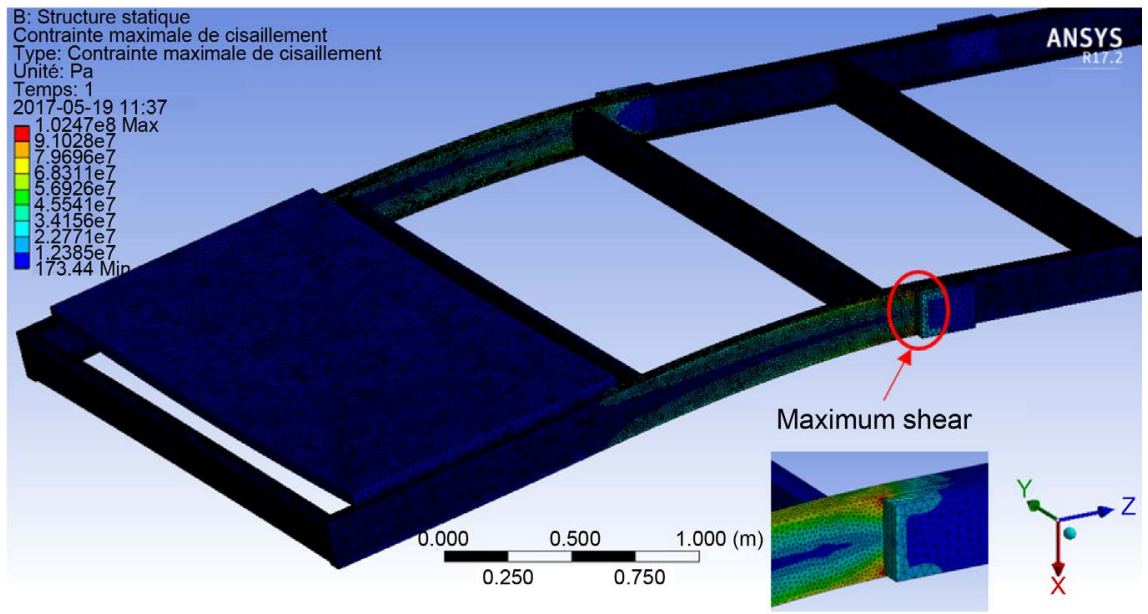

(d)

Figure 12. Equivalent stress, total displasment and shear stress of the 6061-T6 aluminum bus frame. (a) Von Mises equivalent stress analyses. (b) Von Mises equivalent stress analyses. (c) Total displasment. (d) Equivalent stress, total displasment and shear stress of the 6061-T6 aluminum bus frame.

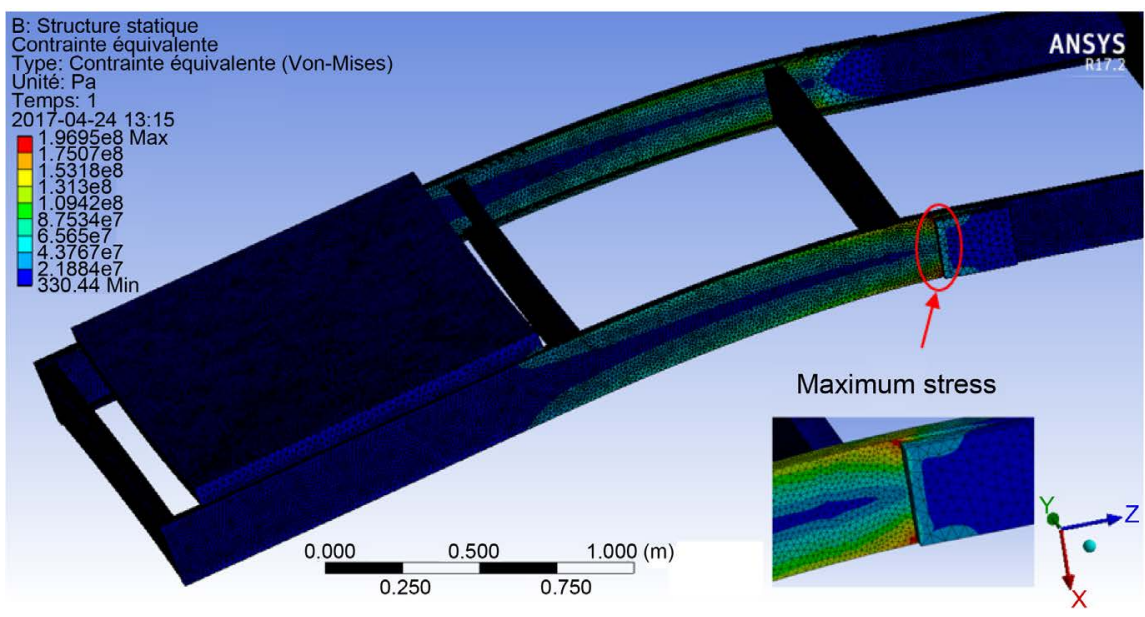

(a)

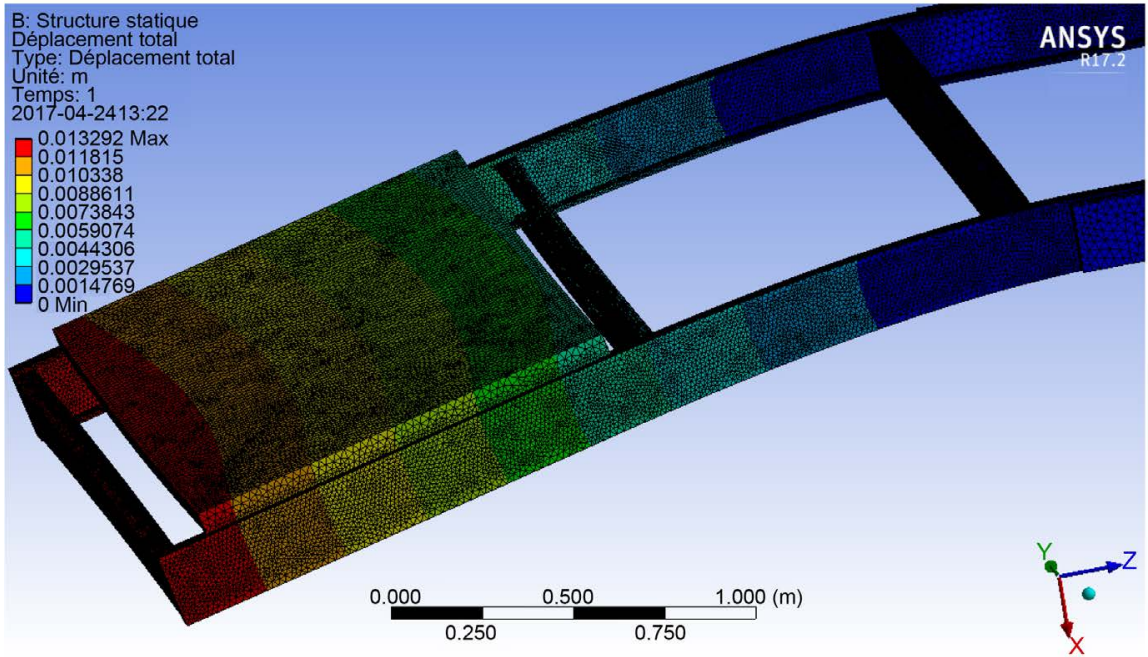

(b) 


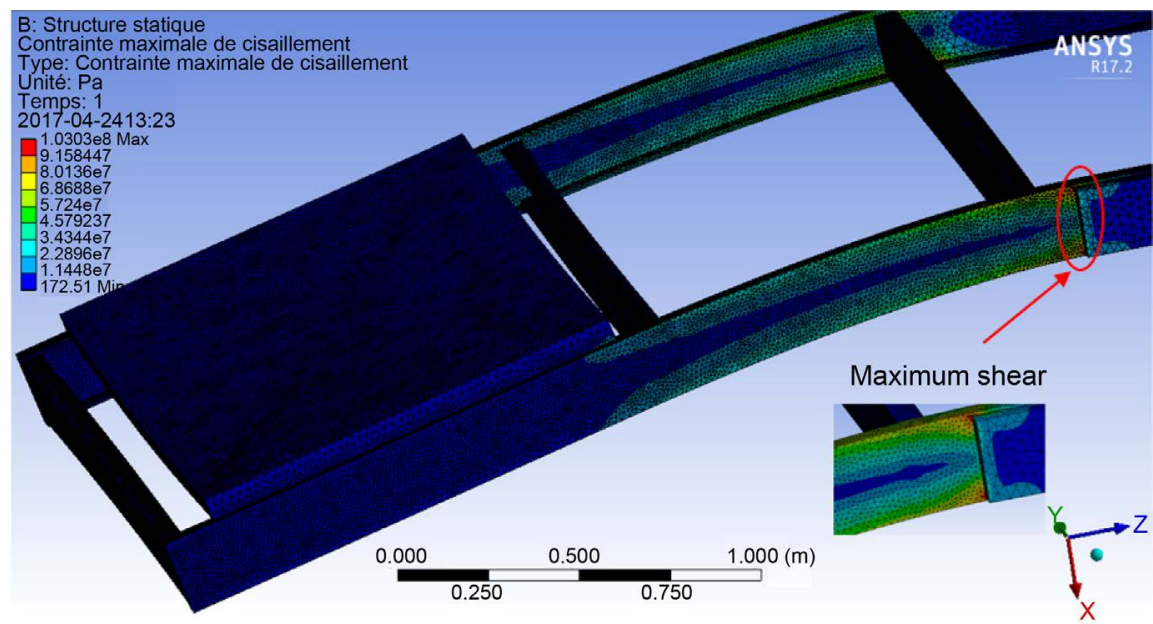

(c)

Figure 13. Equivalent stress, total displasment and shear stress of the 1018-HR steel bus frame. (a) Von Mises equivalent stress. (b) Total displasment. (c) Maximum shear stress.

Table 5. Static analysis results of the bus frame for the three materials.

\begin{tabular}{cccc}
\hline Static analysis & $6061-\mathrm{T} 6$ & $1018-\mathrm{HR}$ & $710 \mathrm{C}$ \\
\hline Equivalent stress $(\mathrm{MPa})$ & 195.30 & 197.00 & 197.00 \\
Total displacement (m) & 0.038 & 0.013 & 0.013 \\
Shear stress $(\mathrm{MPa})$ & 102.50 & 103.03 & 103.03 \\
\hline
\end{tabular}

freedom are free to be able to evaluate the natural response of chassis frame. If one of the natural frequencies coincides with the frequency of the excitation rod, then resonance phenomena may occur with system breaks. Figure 14 shows the first bending and torsion vibration modes obtained for the aluminum frame. The focus was on the frequency between $1 \mathrm{up}$ to $20 \mathrm{~Hz}$ approximately. The first mode corresponds to the torsion mode at $1.44 \mathrm{~Hz}$. This result is also obtained by 3-D dynamic model presented in the section 3.2 that was equal to $1.80 \mathrm{~Hz}$ corresponding to the roll motion of the total frame. The first and second bending modes of the total are respectively equal to $9.10 \mathrm{~Hz}$ and $23.27 \mathrm{~Hz}$.

The comparison of the frequency results for the four first vibration modes of the total frame for the three materials is given in Table 6. For the frames made with the 1018-HR and $710 \mathrm{C}$ steel, the natural frequencies are the same. With the comparison of the aluminum and steel frames frequencies, the differences are small. Then it is possible to conclude that for modal analysis, the use of aluminum instead of steel does not affect the results.

\section{Conclusions}

Static and vibratory comparisons were made for a bus frame designed using three materials that are 6061-T6 aluminum, 1018-HR steel and 710C steel. The results analysis of the static study shows that the aluminum frame presents 

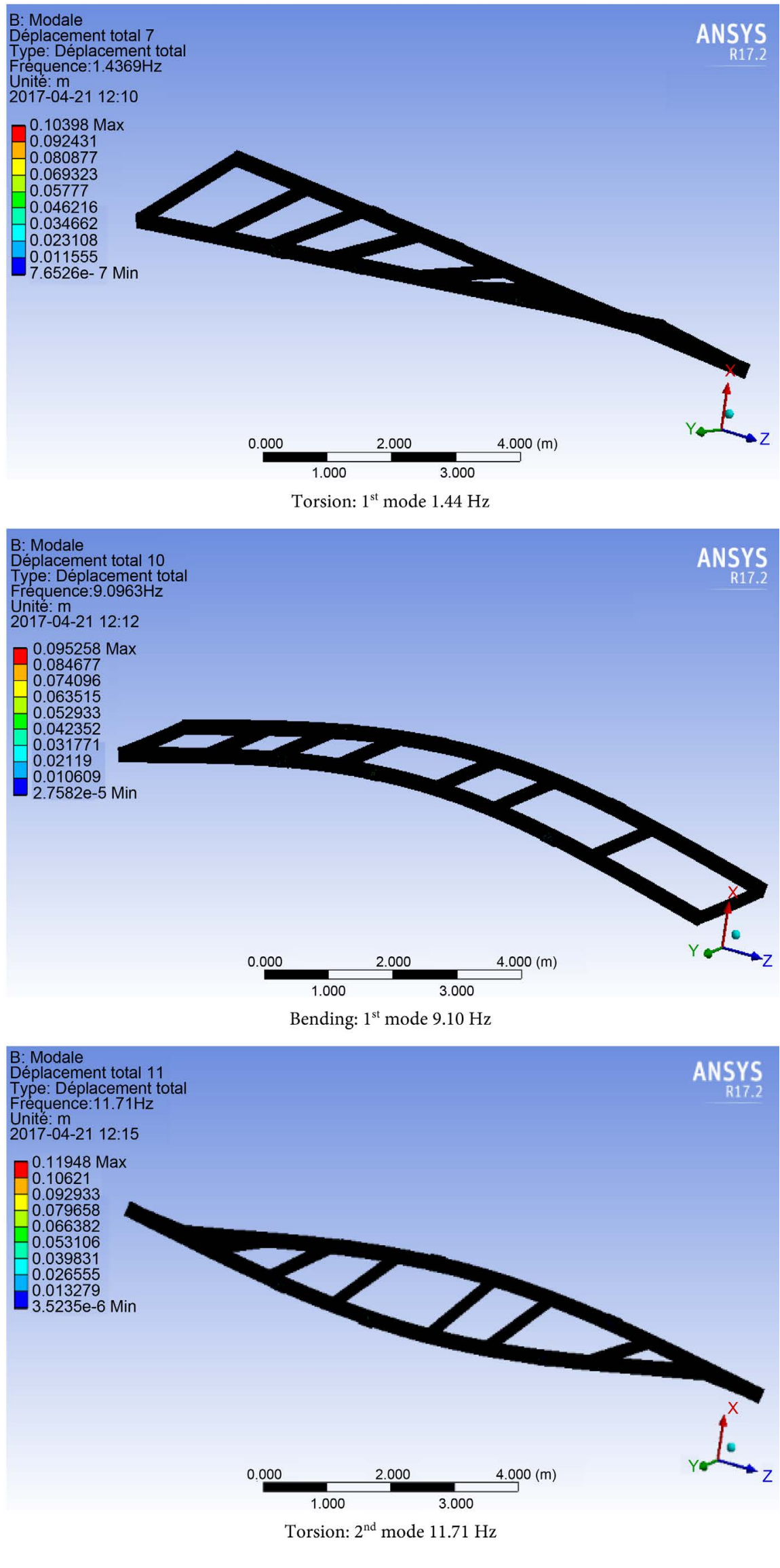


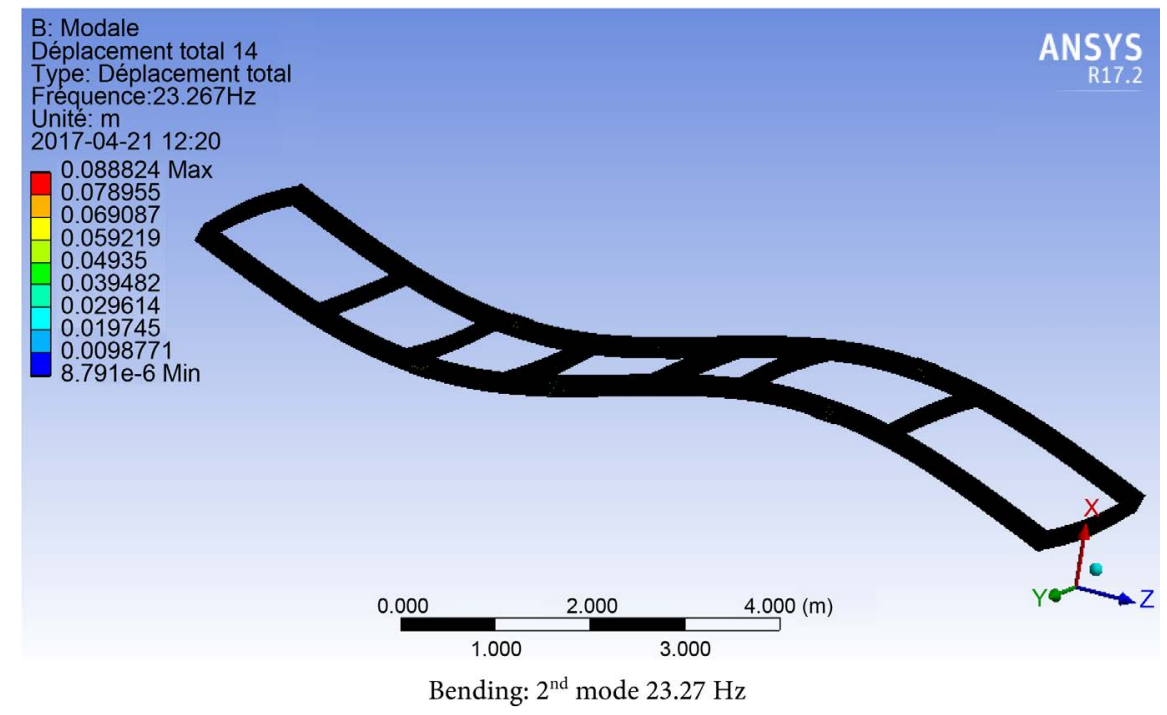

Figure 14. Vibration modes aluminium 6061-T6 frame.

Table 6. Vibration modes aluminum and steel frames.

\begin{tabular}{cccc}
\hline & \multicolumn{3}{c}{ Frequency $(\mathrm{Hz})$} \\
\cline { 2 - 4 } Vibration modes & $6061-\mathrm{T} 6$ & $1018-\mathrm{HR}$ & $710 \mathrm{C}$ \\
\hline Torsion- $1^{\text {st }}$ mode & 1.44 & 1.46 & 1.46 \\
Bending- $^{\text {st }}$ mode & 9.10 & 9.18 & 9.18 \\
Torsion-2 $^{\text {nd }}$ mode & 11.71 & 11.83 & 11.83 \\
Bending-2 $^{\text {nd }}$ mode & 23.27 & 23.51 & 23.51 \\
\hline
\end{tabular}

stresses in the same order as those of steel. The generated shear and Von Mises stresses are less than the permissible value so the design is safe for all three materials. Knowing that the 6061-T6 aluminum has the same elastic limit stress as the 1018-HR steel which is equal to $275 \mathrm{MPa}$, both frames will have the same behavior. Then, it is possible to replace the steel frame with that of aluminum, knowing that the latter can fulfill functions equivalent to that of steel in addition to bringing many more advantages such as flexibility, lightness, a gain at the level of the energy consumption in addition to a high resistance to corrosion.

As for the vibratory study, the results also show a very great similarity between the frames designed in aluminum in comparison with those made of steel. This study was carried out dynamically and numerically. So, the change of material does not really affect the vibratory behavior in the design of a frame.

\section{Acknowledgements}

The financial support of the Aluminium Research Center (REGAL) is greatly appreciated.

\section{References}

[1] Chandrasekar, M., Premraj, R. and Palpandi, K. (2016) A Review on Design Modi- 
fication and Analysis of Chassis Frame. South Asian Journal of Engineering and Technology, 2, 47-52.

[2] Patil, M., Thakare, R. and Bam, A. (2015) Analysis of a Tanker Truck Chassis. International Journal on Mechanical Engineering and Robotics, 3, 20-24.

[3] Udhay Kiran, S. and Mahesh Kumar, M. (2016) Linear Static Analysis of Truck Chassis. International Journal of Innovative Research in Science Engineering and Technology, 5, 15713-15719.

[4] Bajwa, M.S., Pundir, S. and Joshi, A. (2013) Static Load Analysis of Tata Super Ace Chassis and Stress Optimisation using Standard Techniques. International Journal of Mechanical and Production Engineering, 1, 50-54.

[5] Fui, T.H. and Rahman, R.A. (2007) Statics and Dynamics Structural Analysis of a 4.5-Ton Truck Chassis. Jurnal Mekanikal, No. 24, 56-67.

[6] Rahman, R.A., Tamin, M.N. and Kurdi, O. (2008) Stress Analysis of Heavy Duty Truck Chassis as a Preliminary Data for Its Fatigue Life Prediction using FEM. Jurnal Mekanikal, No. 26, 76-85.

[7] Patel, V.V. and Patel, R.I. (2012) Structural Analysis of a Ladder Chassis Frame. World Journal of Science and Technology, 2, 5-8.

[8] Khannukar, K., Kallannavar, V. and Manjunath, B.S. (2015) Dynamic Analysis of Automotive Chassis Using FEA. International Research Journal of Engineering and Technology, 2, 2165-2170.

[9] Ravi Chandra, M., Sreenivasulu, S. and Altaf Hussain, S. (2012) Modeling and Structural Analysis of Heavy Vehicle Chassis Made of Polymeric Composite Material by Three Different Cross Sections. International Journal of Modern Engineering Research, 2, 2594-2600.

[10] Jain, A. and Seshagiri Rao, G.V.R. (2016) Stress and Weight Analysis of Ladder Frame of Light Duty Truck. International Journal of Engineering Sciences \& Management, 6, 118-128.

[11] Patel Vijaykumar, V. and Patel, R.I. (2012) Structural Analysis of Automotive Chassis Frame and Design Modification for Weight Reduction. International Journal of Engineering Research \& Technology, 1, 1-6.

[12] Swami, K.I. and Tuljapure, S.B. (2014) Analysis of Ladder Chassis of Eicher 20.16 using FEM. Journal of Applied Geology and Geophysics, 2, 6-13.

[13] Godse, S. and Patel, D.A. (2013) Static Load Analysis of Tata Ace Ex Chassis and Stress Optimisation Using Reinforcement Technique. International Journal of Engineering Trends and Technology, 4, 3037-3039.

[14] Patil, H.B., Kachave, S.D. and Deore, E.R. (2013) Stress Analysis of Automotive Chassis with Various Thicknesses. Journal of Mechanical and Civil Engineering, 6, 44-49. https://doi.org/10.9790/1684-0614449

[15] Irshad, K. and Vamsi Krishna, M. (2014) Analysis of Chassis with \& without Stiffener Using FEM. International Journal of Mechanical Engineering and Robotics Research, 3, 390-394.

[16] Singh, A., Soni, V. and Singh, A. (2014) Structural Analysis of Ladder Chassis for Higher Strength. International Journal of Emerging Technology and Advanced Engineering, 4, 253-259.

[17] Francis, V., Rai, R.K., Singh, A.K., Singh, P.K. and Yadav, H. (2014) Structural Analysis of Ladder Chassis Frame for Jeep Using Ansys. International Journal of Modern Engineering Research, 4, 41-47. 
[18] Hari Kumar, A. and Deepanjali, V. (2016) Design \& Analysis of Automobile Chassis. International Journal of Engineering Science and Innovative Technology, 5, 187-196.

[19] Iveco Trucks Australia Limited (2009) Intercity/Tourist Coach Specifications.

[20] Ministère des transports du Québec (2005) Guide des normes de charges et dimension des véhicules.

[21] Mohamed Bouazara (1997) Étude et analyse de la suspension active et semi-active des véhicules routiers. $\mathrm{PhD}$ Thesis, Laval University, Québec. 